\title{
Correction to: Cloud-based vehicular networks: a taxonomy, survey, and conceptual hybrid architecture
}

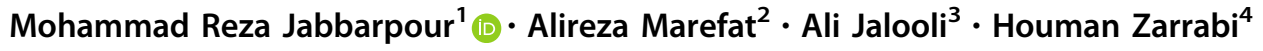

Published online: 29 November 2017

(C) Springer Science+Business Media, LLC, part of Springer Nature 2017

\section{Correction to: Wireless Netw \\ https://doi.org/10.1007/s11276-017-1563-5}

The original version of this article unfortunately contained a mistake in the title. The correct title has been published with this erratum.

The original article can be found online at https://doi.org/10.1007/s11276-017-1563-5.

Mohammad Reza Jabbarpour

mr.jabbarpour@iau-tnb.ac.ir

1 Department of Computer Engineering, Islamic Azad

University North Tehran Branch, Tehran, Iran

2 Faculty of Computer Science and Information Technology,

University of Malaya, 50603 Kuala Lumpur, Malaysia

3 Department of Computer Science, Michigan Technological University, Houghton, MI 49931, USA

4 Iran Telecommunication Research Center (ITRC), Tehran 14155-3961, Iran 